to the late Prof. E. D. Merrill. The following have been elected correspondants for the Zoology Section of the Academy : Prof. U. d'Ancona, professor of zoology in the University of Padua, in succession to Prof. D. Keilin, recently elected a foreign associate of the Academy ; and Prof. P. Brien, professor of zoology in the University of Brussels, in succession to Prof. A. Vandel, recently elected a non-resident member of the Academy.

\section{Recent Economies in Government Expenditure}

THE Chancellor of the Exchequer, Mr. H. Macmillan, made a statement about economies in government expenditure on June 26 , in which he said that the estimated savings in defence $(£ 36.5$ million on the defence programme and $£ 14$ million on defence expenditure) do not reflect any change in the size or shape of the Armed Services and that any major decisions in this field would only be taken after consultation with Britain's allies. The savings of $£ 25.5$ million on other Civil Estimates, details of which are given in a paper afterwards circulated, include $£ 810,000$ in grants for Colonial development and welfare, including rescarch, $£ 70,000$ in economies in capital expenditure by the Agricultural Research Council, $£ 53,000$ in economies in training and research and reduction in purchases of equipment by the Forestry Commission, $£ 180,000$ in economies in maintenance expenditure on roads and $£ 150,000$ in general economy by the Department of Scientific and Industrial Research. Economies of $£ 265,000$ by the Ministry of Housing and Local Government are to fall in part on National Parks. From the public point of view, it would seem that, where departments have been efficiently run in the past or have been short of adequate resources, the cuts though small will do real, if only marginal, harm.

\section{Factory Inspectorate of Great Britain}

REPLing to questions in the House of Commons on June 26, the Minister of Labour and National Service, Mr. Tain Macleod, said that, of the ninety-six districts of the Factory Inspectorate, thirty-six have no inspectors possessing university degrees in engineering or chemistry and physics, and only eleven have more than one such inspector. For 1939, when there were ninety-two districts, the corresponding figures were twenty-four and twenty-three. Mr. Macleod said that the question of the technical strength of the Inspectorate is the most important matter now before him as a result of the departmental committee's report, and the problems are being considered whether the establishment of inspectors should be increased and whether more technically qualified people are needed.

\section{National Science Foundation Russian Translation Programme}

Expansion of the U.S. National Science Foundation programme for the translation into English of Russian research literature has recently been made through a grant of 76,500 dollars for this purpose to the American Institute of Physics. The expanded programme will include the Zhurnal Teknicheskoi Fiziki (Journal of Technical Physics), Akusticheskii Zhurnal (Acoustics Journal), and physics articles from the Doklady Akademii Nauk SS'SR (Proceedings of the USSR Academy of Sciences). First issues of the translated journals will appear soon. The Foundation and the American Institute of Physies have already successfully collaborated in the publication of Soviet Physics-JETP, a bi-monthly translation of Zhurnal
Eksperimental noi i Teoreticheskoi Fiziki (Journal of Experimental and Theoretical Physics), six issues of which have now appeared. In addition to the programme in physics, the Foundation is supporting translations of Russian papers in mathematics and biology; and plans for the fiscal year 1957 include the earth seiences and the engineering sciences. The American Mathematical Society publishes about 1,000 pages annually of Russian work in mathematics, under the title, American Mathematical Society Translations. The Foundation has just awarded a small grant to Biological Abstracts for the translation and publication of abstracts from the Russian journal, Referativnyi Zhurnal: Biologiia (Abstract Journal: Biology). During the last half of 1956 some 1,200 abstracts from Russian journals covered by Referativnyi Zhurnal: Biologiia will be translated by Consultants Bureau, Inc., of New York and reprinted in Biological Abstracts. The abstracts will be drawn from thirty-one primary journals covering a wide range in the field of biology.

\section{Science Museum Collection of Time-Measuring Instruments}

THE interest shown in the collection of exhibits at the Science Museum, London, illustrating the measurement of time has called for a third, revised and expanded, edition of the descriptive catalogue of the objects exhibited in the Time Measurement Section of the Museum (pp. $102+10$ plates. London : H.M.S.O., 1955 ; $6 s$. $6 d$. net). The second edition was published in June 1950. Part 1 of the handbook, entitled "Historical Review", which is published separately and which in its third edition was reprinted last in 1952, consists of a brief review of the history of time measurement together with notes on the principles employed in measuring time. Part 2, the "Descriptive Catalogue", contains the substance of the descriptive labels exhibited with the various objects in the Museum. The collection is classified into twelve large groups, which are further divided into sub-groups, and 463 exhibits are listed (compared with 390 in the second edition), together with some eighty other objects not on exhibition. A new section deals with time recorders, that is, instruments which make a printed record of the time of day at which a certain event takes place. Many of the collection of more than seventy sand-glasses, presented to the Museum in 1952 by the Rt. Rev. Abbot Horne, of Downside Abbey, are now included in the Museum exhibition, in addition to several new exhibits in almost every section. The illustrations in the handbook are the same as in the previous edition, but the illustration on the cover has been changed from a reproduction of a sixteenth-century weight-driven domestic clock to that of a 1718 garden sundial. The price is double that of the previous edition.

\section{Rapid Analysis of Silicate Rocks}

DURING recent years the United States Geological Survey has been faced with the problem of achieving a greatly increased output of ehemical analyses at a time when the demand for analytical chemists much exceeded the supply. To circumvent this impasse, rapid analytical methods have had to be devised. The procedures described in Bulletin 1036-C of the Survey, "Rapid Analysis of Silicate Rocks", by Leonard Shapiro and W. W. Brannock (pp. 56. Washington, D.C. : U.S. Government Printing Office, 1956 ; 20 cents), provide for the analysis of the 